\title{
Treatment Options and Outcome of Premature Rupture of Membranes at Zagazig University Hospitals
}

\author{
Ali El-Shabrawy Ali, Hend Salah Abdo, Amira Ehmida Elsayed Elawady*, Ahmed Ismaeil Mohammed \\ Department of Obstetrics and Gynecology, Faculty of Medicine, Zagazig University, Egypt. \\ *Correspondence to: Amira Ehmida Elsayed Elawady, Mobile: (+20)01091804893, E-mail: amiraelawady253@gmail.com
}

\begin{abstract}
Background: PROM "premature rupture of membrane" is defined as a spontaneous leakage of amniotic fluid from the amniotic sac before onset of labor.

Objecitve: The aim of this work was to verify better management and improve outcome of PROM cases. Patients and Methods: A prospective cohort study was conducted at High Risk Pregnancy Room, Emergency Hospital Obstetrics and Gynecology Department, Faculty of Medicine, Zagazig University. It included 80 women with PROM. The study was between August 2019 and March 2020. All patients were subjected to detailed history taking, general, obstetric examination, and laboratory Investigations.

Results: The gestational age at labor was 35.6 weeks compared to gestational age at PROM, which was 34.3 weeks; the difference was statistically significant, mean increase of gestational age was 1.27 weeks. The incidence of postpartum complication was $1.25 \%$ of mothers in the form of chorioamnionitis.

Conclusions: that conservative procedures like antibiotics, corticosteroids, tocolytics and magnesium sulphate could prolong latency period, improves the fetomaternal outcome and decreases the need for incubators.
\end{abstract}

Keywords: Abortion, Premature Rupture of Membranes, Risk Factors.

\section{INTRODUCTION}

A premature rupture of membranes (PROM) is defined as a spontaneous leakage of amniotic fluid before onset of labor. Preterm PROM occurs after 28 weeks of gestational age and before 37 weeks. Term PROM occurs after 37 completed weeks of gestational age including postterm cases occurring after 40 weeks. Differentiating between PROM and PPROM has mainly got therapeutic consequence, as it enables to decide on appropriate intervention prolonging pregnancy or initiating birth. Preterm PROM and term PROM can be divided into early PROM: less than 12 hours has passed since the rupture of fetal membrane and prolonged PROM: 12 or more hours has passed since the rupture of fetal membranes ${ }^{(\mathbf{1})}$.

Premature rupture of membrane (PROM), which is a spontaneous rupture of membrane is a normal component of labor and delivery. Preterm PROM complicates $3-8 \%$ of pregnancies and leads to one third of preterm deliveries. It increases the risk of prematurity and leads to other perinatal and neonatal complications with $1-2 \%$ risk of fetal death ${ }^{(2)}$.

Rupture of the fetal membranes can occur when the cervix is either closed or dilated. Sometimes, it can occur in a very early pregnancy (before twenty-eight weeks this leads to inevitable abortion). Risk factors highly associated with PROM: Infection, malpresentation of the fetus, multiple pregnancy, excess amniotic fluid, cervical incompetence, and trauma to the abdomen. When there is a rupture in the fetal membranes, the woman notices a painless sudden leakage of fluid from her vagina, which is usually excess and watery. However, when the amount of amniotic fluid in the sac is minimal, the leaking fluid may only wet her underwear, and you may be unsure whether to make the diagnosis of PROM from the woman's complaint ${ }^{(3)}$.

The causes of PROM are unclear. But $\mathrm{PROM} / \mathrm{PPROM}$ is more likely to happen in women who: Had prior PPROM, had prior preterm labor and delivery, have an infection in the vagina or uterus (chorioamnionitis, group B streptococcus, bacterial vaginosis, urinary tract infections), have bleeding from the vagina, smoking, have poor nutrition, have had previous cervical surgery, including cone biopsies or cerclage, have had overstretching of the uterus and amniotic sac, which sometimes occurs with multiple fetuses or too much amniotic fluid (hydramnios) ${ }^{(4)}$.

For treatment of these cases, delivery if there is fetal compromise, infection, or gestational age $\geq 34$ weeks, otherwise, the woman's activity is limited to modified bed rest, antibiotics and corticosteroids should be given ${ }^{(5)}$.

Intravenous magnesium sulfate should be considered in pregnancies $<32$ weeks, use of tocolytics is controversial $^{(6)}$. PROM management requires balancing risk of infection when delivery is delayed with risks due to fetal immaturity when delivery is immediate. So, the aim of this study was to verify better management and improve outcome of PROM cases.

\section{PATIENTS AND METHODS}

This study was carried out at High Risk Pregnancy Room, Emergency Hospital Obstetrics and Gynecology Department, Faculty of Medicine, Zagazig University. All patients were asked to fill the questionnaire, physical examination was done and sterile Cusco speculum was conducted. 


\section{Ethical considerations:}

Written informed consent was obtained from all patients. The study was approved by the Research Ethical Committee of Faculty of Medicine, Zagazig University. The work was carried out for studies involving humans in accordance with the World Medical Association's Code of Ethics (Helsinki Declaration).

Sample size: Assuming that the number of patient with premature rupture of membrane is 100 patient/year and frequency of neonatal pneumonia is $58 \%$ so that sample size is 80 patients using open Epi-program at confidence level $95 \%$.

Inclusion Criteria: Pregnancy between 28-42 weeks of gestation. Women willing to participate in the study. Women with PROM leaking from cervix confirmed by speculum examination. Prim and multigravida.

Exclusion Criteria: Intrauterine growth restriction. Antepartum hemorrhage. Major fetal congenital anomalies.

All patients were subjected to detailed history taking including (age, job, race, socioeconomic status, duration of marriage, consanguinity, and smoking status). Passage of liquor from the vagina. Gravidity, parity and abortion (duration of pregnancy, mode of termination (spontaneous, induced), Previous history of PPROM, gestational age at delivery in weeks, type of pregnancy (single, twins, triple...), type of PPROM, latency period. Maternal outcomes: Mode of delivery (spontaneous vaginal or cesarean section (CS) delivery), presence of clinical chorioamnionitis, which is characterized by maternal fever $\left(>39^{\circ} \mathrm{c}\right)$ accompanied by at least two of the following signs: maternal or fetal tachycardia, maternal leukocytosis, uterine tenderness, or foul-smelling amniotic fluid.

Neonatal outcome: Birth weight "in Kgs", alive and well, alive but needed (NICU) admission, neonatal death or others. Full clinical physical examination including general examination (Blood pressure, pulse, temperature, respiratory rate, previous scar) and obstetric examination; Inspection of the abdomen of the patient in the left lateral position "tilting $15^{\circ}$ to the horizontal level" to avoid the aortocaval compression "as the gravid uterus compresses abdominal aorta and inferior vena cava". The abdomen was exposed from xiphisternum to the symphysis pubis. Inspection of the abdomen for abdominal shape, fetal movement, linea nigra, surgical scars, striae gravidarum, striae albicans.

Detection of watery discharge from the vagina confirmed by a sterile speculum and observation of fluids accumulated in the posterior vaginal fornix or direct leakage from the cervical canal when pressure on the fundus.

Laboratory Investigations included; Complete blood count (CBC), C-reactive protein (CRP), Erythrocyte Sedimentation Rate (ESR), Vaginal smear for culture and sensitivity. Nitrazine test in which colour turn to deep blue from yellow due to alkalinity of amniotic fluid. Visualization fern like pattern on glass due to presence of protein and $\mathrm{NaCl}$ crystal. Visualization of fern like pattern on glass under light microscope. Amniotic fluid culture and urine culture. Sonographic examination for viability, amniotic fluid (AF), placental site, and gestational age.

\section{Follow-up of the patients:}

Measuring the maternal temperature, evaluating uterine tenderness, and performing fetal heart rate monitoring twice a day. Maternal leucocytic count and blood sedimentation speed were measured every two days. Once a week an ultrasound examination was performed to check fetal wellbeing. A cervical/vaginal culture was also done once a week to certify a local sterilization, In case of resistance to ampicillin, the antibiotic treatment was adapted.

\section{Statistical Analysis}

All data were collected, tabulated and statistically analyzed using SPSS 20.0 for windows (SPSS Inc., Chicago, IL, USA2011). Quantitative data were expressed as the mean \pm SD and median (range), and qualitative data were expressed as absolute frequencies (number) and relative frequency (percentage). Continuous data were checked for normality by using Shapiro Wilk test. Paired t-test was used to compare between two dependent variables of normally distributed variables. Percent of categorical variables were compared using Chi-square test or Fisher' exact test when appropriate. P-value $<0.05$ was considered statistically significant.

\section{RESULTS}

Table 1 shows the demographic and obstetric history of the studied women.

Table (1): Demographic criteria and obstetric history of the studied women $(n=80)$

\begin{tabular}{|c|c|}
\hline Variables & \\
\hline $\begin{array}{c}\text { Age (years) } \\
\text { Mean } \pm \text { SD } \\
\text { Range }\end{array}$ & $26.4 \pm 6.7$ \\
$17-47$ \\
\hline $\begin{array}{c}\text { Gravidity } \\
\text { Median } \\
\text { (range) }\end{array}$ & $\mathbf{1}(\mathbf{1 - 8})$ \\
\hline $\begin{array}{c}\text { Body mass index } \\
\text { Mean } \pm \text { SD } \\
\text { Range }\end{array}$ & $27 \pm 7.6$ \\
& $(19-35)$ \\
\hline
\end{tabular}

n: Number

Table 2 shows that participant's obstetric history. $49.1 \%$ of them had history of PROM. 
Table (2): Obstetric history of the studied women $(n=80)$

\begin{tabular}{|c|c|c|c|}
\hline & Variables & n & $\%$ \\
\hline \multirow{3}{*}{ Parity } & Primipara & 25 & \\
\hline & Multipara & 55 & \\
\hline & Median(range) & $2(0-6)$ & \\
\hline \multirow{2}{*}{$\begin{array}{c}\text { Previous } \\
\text { delivery }(n=55)\end{array}$} & Vaginal delivery & 24 & $43.60 \%$ \\
\hline & $\mathrm{CS}$ & 31 & $56.40 \%$ \\
\hline \multirow{2}{*}{$\begin{array}{c}\text { History of } \\
\text { abortions }(n=55)\end{array}$} & Yes & 22 & $40 \%$ \\
\hline & No & 33 & $60 \%$ \\
\hline \multirow{2}{*}{$\begin{array}{l}\text { History of preterm } \\
\text { labor }(n=55)\end{array}$} & Yes & 25 & $45.45 \%$ \\
\hline & No & 30 & $55.55 \%$ \\
\hline \multirow{2}{*}{$\begin{array}{c}\text { History of PROM } \\
(n=55)\end{array}$} & Yes & 27 & $49.10 \%$ \\
\hline & No & 28 & $50.90 \%$ \\
\hline
\end{tabular}

n: Number, CS: Cesarean Section

Table 3 shows that gestational age at labor was significantly higher compared to gestational age at PROM.

Table (3): Comparison between gestational age at PROM and at labor per weeks of the studied women $(\mathrm{n}=80)$

\begin{tabular}{|c|c|c|c|c|}
\hline & $\begin{array}{c}\text { Gestational } \\
\text { age at } \\
\text { PROM per } \\
\text { weeks }\end{array}$ & $\begin{array}{c}\text { Gestational } \\
\text { Age at } \\
\text { labor per } \\
\text { weeks }\end{array}$ & $\begin{array}{c}\text { Mean } \\
\text { difference }\end{array}$ & P \\
\hline $\begin{array}{c}\text { Gestational age } \\
\text { Mean } \pm \text { SD }\end{array}$ & $34.3 \pm 2.6$ & $35.6 \pm 2.4$ & 1.27 & 0.0001 \\
\hline
\end{tabular}

n: Number

Table 4 shows that the incidence of postpartum complication was $1.25 \%$ of mothers in the form of chorioamnionitis.

Table (4): Maternal outcome of conservative management of PROM among studied women $(n=80)$

\begin{tabular}{|l|c|c|}
\hline & $\mathbf{n}$ & $\%$ \\
\hline Mode of delivery in the & & \\
current pregnancy: & 55 & $68.75 \%$ \\
1-Term delivery: & 9 & $11.25 \%$ \\
$\quad$-Vaginal delivery. & 46 & $57.5 \%$ \\
-CS. & 25 & $31.25 \%$ \\
2-Preterm delivery: & 10 & $12.5 \%$ \\
-Vaginal delivery. & 15 & $18.75 \%$ \\
-CS. & 1 & $1.25 \%$ \\
Chorioamnionitis: & 79 & 98.75 \\
$\quad$ Yes & 0 & 0 \\
\hline No & 0 & 0 \\
\hline Puerperal sepsis & & \\
\hline Deep venous thrombosis & & \\
\hline
\end{tabular}

n: Number, CS: Cesarean Section
Table 5 shows that the frequency of some risk factors associated with PROM.

Table (5): Frequency distribution of some risk factors associated with outcome among women with of PROM $(\mathrm{n}=80)$

\begin{tabular}{|c|c|c|}
\hline Risk factors & $\mathbf{n}$ & $\%$ \\
\hline \multicolumn{3}{|l|}{ Age per years } \\
\hline$\leq 18$ & 4 & $5.0 \%$ \\
\hline $19-35$ & 67 & $83.75 \%$ \\
\hline$>35$ & 9 & $11.25 \%$ \\
\hline Special habit & & . \\
\hline $\begin{array}{l}\text { Smoker } \\
\text { Non smokers }\end{array}$ & $\begin{array}{c}1 \\
79\end{array}$ & $\begin{array}{r}1.25 \% \\
98.75 \%\end{array}$ \\
\hline Parity & & . \\
\hline Primipara & 25 & $31.25 \%$ \\
\hline Multipara & 55 & $68.75 \%$ \\
\hline Socioeconomic & & . \\
\hline Low & 31 & $38.75 \%$ \\
\hline Good & 49 & $61.25 \%$ \\
\hline $\begin{array}{l}\text { Interpregnancy } \\
\text { interval }(n=55)\end{array}$ & & $\cdot$ \\
\hline$<2 \mathrm{y}$ & 21 & $38.2 \%$ \\
\hline$\geq 2 y$ & 34 & $61.8 \%$ \\
\hline Twins & & . \\
\hline Yes & 5 & $6.25 \%$ \\
\hline $\mathrm{No}$ & 75 & $93.75 \%$ \\
\hline $\begin{array}{l}\text { History of PROM } \\
(n=55)\end{array}$ & & . \\
\hline Yes & 27 & $49.1 \%$ \\
\hline No & 28 & $50.9 \%$ \\
\hline Infection & & . \\
\hline Yes & 32 & $40.00 \%$ \\
\hline No & 48 & $60.00 \%$ \\
\hline Multipara $(n=55)$ & & . \\
\hline Previous CS & 31 & $56.4 \%$ \\
\hline Vaginal delivery & 24 & $43.6 \%$ \\
\hline
\end{tabular}

n: Number, CS: Cesarean Section

Table 6 shows obviously that CS was done for women with previous history of Cs. 
Table (6): Relation between some risk factors and current method of delivery of studied women $(\mathrm{n}=80)$

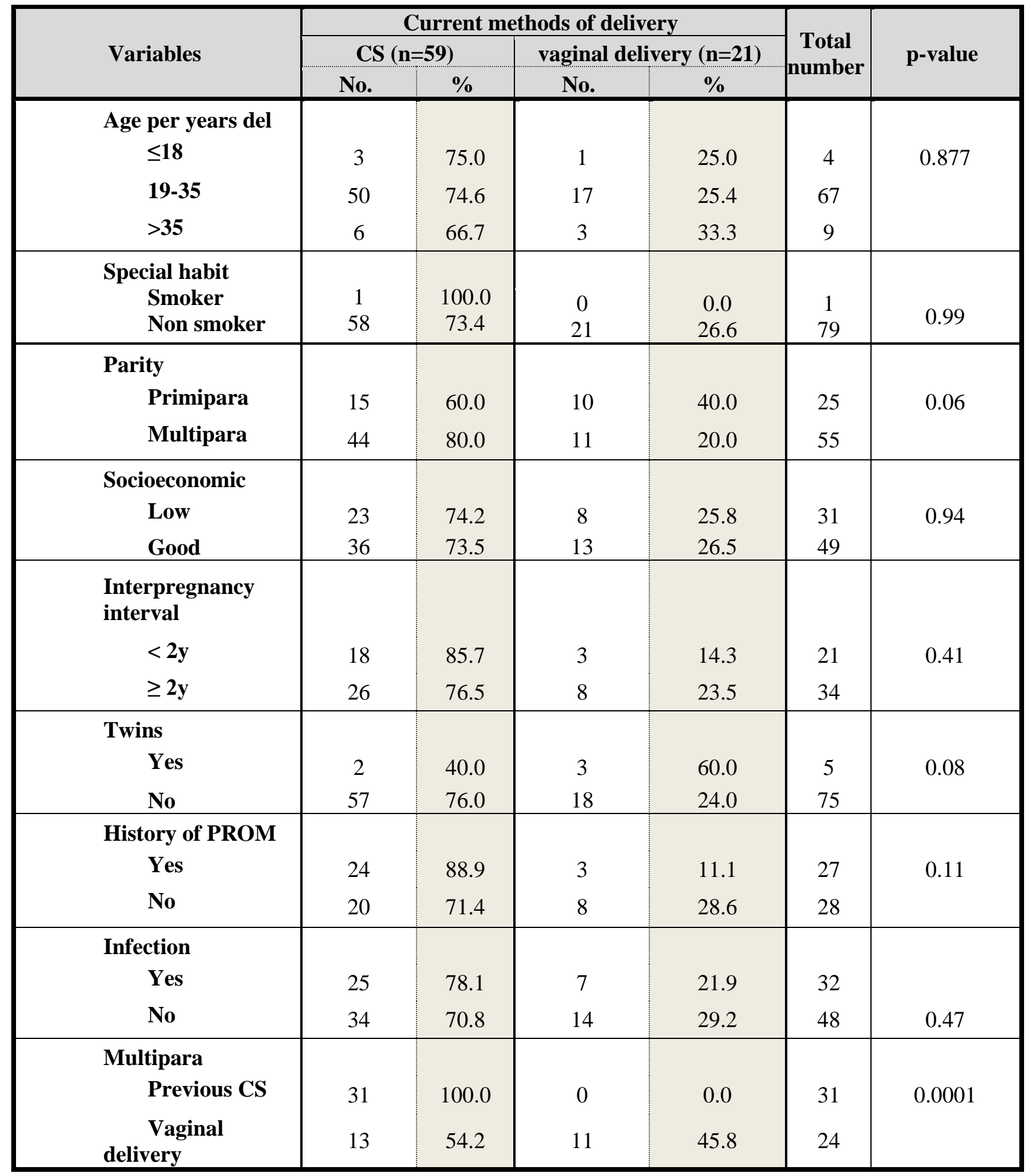

n: Number, CS: Cesarean Section

Table 7 shows obviously that delivery of twins of women with PROM at current pregnancy was associated with put baby on incubator. 
Table (7): Relation between some risk factors and put baby on incubator of studied women (n. 80)

\begin{tabular}{|c|c|c|c|c|c|c|}
\hline \multirow{3}{*}{ Parameters } & \multicolumn{4}{|c|}{ Put baby on incubator } & \multirow{3}{*}{$\begin{array}{c}\text { Total } \\
\text { number }\end{array}$} & \multirow{3}{*}{ p-value } \\
\hline & \multicolumn{2}{|c|}{ Yes } & \multicolumn{2}{|c|}{ No } & & \\
\hline & $\mathbf{n}$ & $\%$ & $\mathbf{n}$ & $\%$ & & \\
\hline $\begin{array}{c}\text { Age per years } \\
\leq 18 \\
\quad 19-35 \\
>35\end{array}$ & $\begin{array}{c}1 \\
22 \\
2\end{array}$ & $\begin{array}{l}25.0 \\
32.8 \\
22.2\end{array}$ & $\begin{array}{c}3 \\
45 \\
7\end{array}$ & $\begin{array}{l}75.0 \\
67.2 \\
77.8\end{array}$ & $\begin{array}{c}4 \\
67 \\
9\end{array}$ & 0.78 \\
\hline $\begin{array}{l}\text { Special habit } \\
\text { Smoker } \\
\text { Non smokers }\end{array}$ & $\begin{array}{c}1 \\
24\end{array}$ & $\begin{array}{c}100.0 \\
30.4\end{array}$ & $\begin{array}{c}0 \\
55\end{array}$ & $\begin{array}{c}0.0 \\
69.6\end{array}$ & $\begin{array}{c}1 \\
79\end{array}$ & 0.99 \\
\hline $\begin{array}{l}\text { Parity } \\
\text { Primipara } \\
\text { Multipara } \\
\end{array}$ & $\begin{array}{c}7 \\
18 \\
\end{array}$ & $\begin{array}{l}28.0 \\
32.7 \\
\end{array}$ & $\begin{array}{l}18 \\
37 \\
\end{array}$ & $\begin{array}{l}72.0 \\
67.3 \\
\end{array}$ & $\begin{array}{l}25 \\
55\end{array}$ & 0.67 \\
\hline $\begin{array}{l}\text { Socioeconomic } \\
\text { Low } \\
\text { Good }\end{array}$ & $\begin{array}{c}9 \\
16\end{array}$ & $\begin{array}{l}29.0 \\
32.7\end{array}$ & $\begin{array}{l}22 \\
33\end{array}$ & $\begin{array}{l}71.0 \\
67.3\end{array}$ & $\begin{array}{l}31 \\
49\end{array}$ & 0.73 \\
\hline $\begin{array}{l}\text { Interpregnancy interval } \\
\quad<2 \mathrm{y} \\
\geq 2 \mathrm{y}\end{array}$ & $\begin{array}{c}8 \\
10\end{array}$ & $\begin{array}{l}38.1 \\
29.4\end{array}$ & $\begin{array}{l}13 \\
24 \\
\end{array}$ & $\begin{array}{l}61.9 \\
70.6 \\
\end{array}$ & $\begin{array}{l}21 \\
34 \\
\end{array}$ & 0.51 \\
\hline $\begin{array}{l}\text { Twins } \\
\text { Yes } \\
\text { No }\end{array}$ & $\begin{array}{c}5 \\
20 \\
\end{array}$ & $\begin{array}{c}100.0 \\
26.7 \\
\end{array}$ & $\begin{array}{c}0 \\
55 \\
\end{array}$ & $\begin{array}{c}0.0 \\
73.3 \\
\end{array}$ & $\begin{array}{c}5 \\
75 \\
\end{array}$ & 0.002 \\
\hline $\begin{array}{l}\text { History of PROM } \\
\text { Yes } \\
\text { No }\end{array}$ & $\begin{array}{l}9 \\
9 \\
\end{array}$ & $\begin{array}{l}33.3 \\
32.1 \\
\end{array}$ & $\begin{array}{l}18 \\
19 \\
\end{array}$ & $\begin{array}{l}66.7 \\
67.9 \\
\end{array}$ & $\begin{array}{l}27 \\
28 \\
\end{array}$ & 0.93 \\
\hline $\begin{array}{l}\text { Infection } \\
\text { Yes } \\
\text { No }\end{array}$ & $\begin{array}{c}8 \\
17 \\
\end{array}$ & $\begin{array}{l}25.0 \\
35.4 \\
\end{array}$ & $\begin{array}{l}24 \\
31 \\
\end{array}$ & $\begin{array}{l}75.0 \\
64.6 \\
\end{array}$ & $\begin{array}{l}32 \\
48 \\
\end{array}$ & 0.33 \\
\hline $\begin{array}{l}\text { Multipara } \\
\text { Previous CS } \\
\text { Vaginal Delivery }\end{array}$ & $\begin{array}{c}10 \\
8 \\
\end{array}$ & $\begin{array}{l}32.3 \\
33.3 \\
\end{array}$ & $\begin{array}{l}21 \\
16 \\
\end{array}$ & $\begin{array}{l}67.7 \\
66.7 \\
\end{array}$ & $\begin{array}{l}31 \\
24 \\
\end{array}$ & 0.93 \\
\hline
\end{tabular}

n: Number, CS: Cesarean Section

\section{DISCUSSION}

The studied cases $(n=80)$ had mean age of $26.4(+6.7 \mathrm{SD})$ with range (17- 47), there were 4 cases had age less than or equal to 18 years $(5 \%)$ and 67 cases had age (19-35) years (83.75\%) and 9 cases had age more than 35 years $(11.25 \%)$. 25 cases were primigravida $(31.25 \%)$. Our results are in agreement with study of Linehan $\boldsymbol{e t} \mathbf{a l} .^{(3)}$ which was done at Cork University Maternity Hospital on 42 cases of spontaneous PROM. The incidence of PROM was most common in age group of $19-42$ years $(74.6 \%)$ and common with primigravida, the same is also reported by Maryuni and Kurniasih ${ }^{(2)}$ as they reported in their study that patients were younger than 20 years and older than 35 years.

In our study, women with low socioeconomic level accounts for $(38.75 \%)$ of cases, this is consistent with Sultana and Karmokar ${ }^{(7)}$ who found that the majority of the women came from lower middle and poor class of the society. The same was reported by Endale $\boldsymbol{e t} \boldsymbol{~ a l}{ }^{(\mathbf{8 )}}$ who found that the majority of PROM cases were women residing in rural areas, had an increased risk of unfavorable maternal outcome 4.2 times higher than those from an urban areas .

In our study, women who had history of PROM were about $(33.75 \%)$ of cases. This was consistent with Hackenhaar $\boldsymbol{e t}$ al. ${ }^{(9)}$ who found that PPROM risk is increased if the mother had previous occurrence of PPROM and the same was proved with Assefa $e t$ al ${ }^{(10)}$ who revealed that previous PROM was a significant risk factor premature rupture of membrane "PROM".

In our study, women who had infection were $40 \%$ of cases. This was consistent with Assefa et al. ${ }^{(\mathbf{1 0 )}}$ who suggested early identification and treatment of genitourinary infection, and the same was proved by Hegazy et al. ${ }^{(11)}$ who found that urinary tract infection, sexually transmitted diseases, lower genital infections (e.g. bacterial vaginosis ) are major risk factors.

In our study using conservative management improved the fetomaternal outcome, this was in agreement with Nagaria $\boldsymbol{e t} \boldsymbol{a l} .{ }^{(\mathbf{1 2})}$ who published that PROM has a poor fetomaternal outcome and to improve 
the outcome of maternal and fetal outcome we need early diagnosis and perfect management. Also, conservative measures and careful surveillance of maternal infection and fetal wellbeing help to improve fetomaternal outcome.

In our study, using corticosteroids improved the neonatal outcome, this was consistent with Battarbee et al. ${ }^{(13)}$ who mentioned that neonates of PROM patients who are exposed to antenatal corticosteroids (2-7) days had a better effect and less respiratory distress syndrome in comparison to the other group who had short or longer time interval between corticosteroids intake and delivery.

In our study we used using antibiotics as a conservative measure to prolong latency and improve fetomaternal outcome. This is in agreement with Caughey et al. ${ }^{(14)}$ who mentioned the effect of broadspectrum antibiotic on PROM remote from term could prolong the latency resulting in a reduction in the delivery within 48 hours by $30 \%$, a reduction in the delivery within 7 days by $20 \%$, an increase in birth weight, a reduction in the risk of chorioamnionitis and an improvement in neonatal complication like a decrease in neonatal sepsis, oxygen requirement and major cerebral abnormalities. The same results were given by Lovereen $\boldsymbol{e t} \boldsymbol{a l}^{\left({ }^{(15)}\right.}$ who published that conservative management (antibiotics and steroids) for PROM patients with gestational age more than 28 weeks to prolong pregnancy, shows significant reduction in maternal and fetal morbidity and mortality

In contrast to our study Walker $\boldsymbol{e t}_{\boldsymbol{a l}}{ }^{(\mathbf{1 6})}$ mentioned that $33 \%$ of infants delivered with longer latency after PROM "more than 28 days" are associated with an increased risk on neonatal mortality and morbidity.

In our study using conservative measures prolonged the latent period as the mean gestational age at PROM was 34.3 wks (+2.6 SD) with range (28-39) weeks and the mean gestational age at labor was 35.6 weeks (+2.4 SD) week with range (29-40) weeks and the mean difference is about 1.27 week, this was in agreement with Test $\boldsymbol{e t} \boldsymbol{a l} .^{(17)}$ who mentioned that the latency period is inversely proportionate with the gestational age and the study did not find any relation between prolonged latency period "more than 72 hours" and increased neonatal mortality rate. The same was proved by Gezer $\boldsymbol{e t}$ al. ${ }^{(\mathbf{1 8})}$ who published a study on 1596 patients with PROM, 1390 patients had an interval less than 4 weeks and 206 patients had an interval more than 4 weeks. Their study showed that prolonged PPROM doesn't increase the risk of neonatal sepsis.

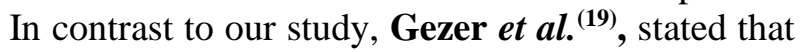
the prolonged latency period following PPROM may be associated with an increase in neonatal morbidity and mortality.

In our study one patient had chorioamnionitis accounts for $(1.25 \%)$ so the use of antibiotic for PROM patients succeeded to eliminate amniotic infection in

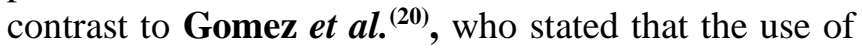

antibiotic for PROM cases failed to eliminate amniotic infection in $83 \%$ of cases.

\section{CONCLUSIONS}

We can conclude that conservative procedures like antibiotics, corticosteroids, tocolytics and magnesium sulphate could prolong latency period, improve the fetomaternal outcome and decreases the need for incubators.

\section{REFERENCES}

1. Mishra S, Joshi M (2017): Premature rupture of membranes "PROM" risk factors "A Clinical study. International Journal OF Contemporary Medical Research, 4: 146-148.

2. Maryuni M, Kurniasih D (2017): risk factors of premature rupture of membrane "PROM". National Public Health Journal, 7: 1-5.

3. Linehan L, Walsh J, Morris A (2016): Neonatal and maternal outcomes following midtrimester preterm premature rupture of the membranes: a retrospective cohort study. BMC Pregnancy Childbirth, 16:25-32.

4. ACOG "American Association of Obstetrics and Gynecologists" Guidance Update (2017): Diagnosis and Management of PROM (Prelabor Rupture of Membrane).

https://www.obgproject.com/2017/12/29/acog-guidanceupdate-diagnosis-management-prom-prelabor-rupturemembranes/

5. Diraviyam J, Karunakaran L (2017): Maternal and perinatal outcome in preterm premature rupture of membranes. International Journal of Reproduction, Contraception, Obstetrics and Gynecology, 6(6): 2498502.

6. Choudhary M, Rathore S, Chowdhary J et al. (2017): Pre and post conception risk factors in PROM. International Journal of Research in Medical Sciences, 3(10):2594-8.

7. Sultana F, Karmokar A (2019): A study on maternal and fetal outcomes of preterm premature rupture of membrane in Tertiary Medical College Banglabesh. https://jmscr.igmpublication.org/home/index.php/archive /159-volume-07-issue-02-february-2019/6655-a-studyon-maternal-and-fetal-outcomes-of-preterm-prematurerupture-of-membrane-in-tertiary-medical-collegebangladesh.

8. Endale T, Fentahun N, Gemada D et al. (2016): Maternal and fetal outcomes in term "PROM" premature rupture of membrane. World Journal of Emergency Medicine, 7(2):147-52.

9. Hackenhaar A, Albernaz E, Fonseca T (2014): Preterm premature rupture of the fetal membranes: association with sociodemographic factors and maternal genitourinary infections. Journal de Pediatric, 90: 197202.

10. Assefa N, Berhe H, Girma F et al. (2018): Risk factors of premature rupture of membranes in public hospitals at Mekele city, Tigray, a case control study. BMC Pregnancy and Childbirth, 18(1): 1-7.

11. Hegazy A (2016): Anatomy and embryology of umbilicus in newborns: a review and clinical correlations. Frontiers of Medicine, 10(3): 271-277.

12. Nagaria T, Diwan C, Jaiswal J (2016): A study on fetomaternal outcome in patients with premature rupture of 
membranes. Int J Reprod Contracept Obstet Gynecol., 5(12): 4123-4127.

13. Battarbee A, Ros S, Esplin $M$ et al. (2020): Optimal timing of antenatal corticosteroid administration and preterm neonatal and early childhood outcomes. American Journal of Obstetrics \& Gynecology MFM., 2(1): 77-82.

14. Caughey A, Robinson J, Norwitz E (2008): Contemporary diagnosis and management of preterm premature rupture of membranes. Reviews in Obstetrics and Gynecology, 1(1): 11-15.

15. Lovereen $S$, Khanum $M$, Nargis $N$ et al. (2018): Maternal and neonatal outcome in premature rupture of membranes. Bangladesh Journal of Medical Science, 17(3): 479-483.

16. Walker M, Picklesimer A, Clark R et al. (2014): Impact of duration of rupture of membranes on outcomes of premature infants. Journal of Perinatology, 34(9): 669672.
17. Test G, Levy A, Wiznitzer A et al. (2011): Factors affecting the latency period in patients with preterm premature rupture of membranes. Archives of Gynecology and Obstetrics, 283(4): 707-710.

18. Drassinower D, Friedman A, Običan S et al. (2016): Prolonged latency of preterm premature rupture of membranes and risk of neonatal sepsis. American Journal of Obstetrics and Gynecology, 214(6): 743-e1.

19. Gezer A, Parafit-Yalciner E, Guralp O et al. (2013): Neonatal morbidity mortality outcomes in pre-term premature rupture of membranes. Journal of Obstetrics and Gynaecology, 33(1): 38-42.

20. Gomez R, Romero R, Gomez R et al. (2007): Antibiotic administration to patients with preterm premature rupture of membranes does not eradicate intra-amniotic infection. The Journal of Maternal-Fetal \& Neonatal Medicine, 20(2): 167-173. 